\title{
Low Shear Mixing
}

National Cancer Institute

\section{Source}

National Cancer Institute. Low Shear Mixing. NCI Thesaurus. Code C113029.

Mixing of solids into liquid, without appreciable size reduction, to form a stable suspension. 